\title{
Discursos de colunas de consultório e subjetividade
}

\author{
Bethania Mariani *
}

\section{Resumo}

O objetivo deste trabalho é apresentar a análise comparativa de consultório psicanalítico. A análise permitiu verificar que tais colunas 1) pasteurizam o discurso da psicanálise; 2) homogeneizam as narrativas feitas nas cartas dos leitores, seja uniformizando as situações apresentadas ou transformando tais narrativas em exemplos de condutas a (não) serem seguidas; 3 ) simplificam as soluções das queixas psicológicas relatadas, inserindo-as em contextos universalizantes, o que produz um efeito de obviedade e naturalização dos sentidos, e 4) traçam fronteiras entre o normal e o patológico, definindo um e outro a partir da descrição/sugestão de determinados comportamentos sociais. Observa-se, desse modo, que o que está em jogo em tais colunas é um processo de representação de sujeito que é construído a partir de um teatro da consciência, ou seja, a partir da construção de evidências de uma identidade que encobre os processos socioideológicos em jogo. Em suma, em nome da psicanálise, tais colunas elaboram formas de comportamento cristalizadas e idealizadas, como se fosse possível atingir um bemestar por meio de modos de agir, pensar e sentir que poderiam/ deveriam ser seguidos por qualquer leitor de tais colunas.

...a promoção do "eu" em nossa existência leva, conforme a concepção utilitarista do homem que a secunda, a realizar cada vez mais o homem como indivíduo. (J. Lacan)'

Tomando como base o quadro teórico-metodológico da análise do discurso, tenho trabalhado objetivando discutir dois eixos, um teórico e outro analítico. Em primeiro lugar, venho discutindo as implicações teórico-metodológicas de um conceito usado por M. Pêcheux em Les vérités de la Palice (1975): "imaginário lingüístico (corpo verbal)"2.

\footnotetext{
* Profa. Dra. da Universidade Federal Fluminense e Pesquisadora do CNPq. A primeira versão deste texto foi apresentada no congresso da ABRALIN, realizado na SBPC, Recife, 2003.
}

Comun. Inf., v. 7, n. 1, p.47-62, jan./jun. 2004 
Afirma o autor que o imaginário lingüístico é o lugar onde se constitui ou, do meu ponto de vista, lugar onde se encontra materializada - a rede de paráfrases e reformulações características de uma formação discursiva. As conexões teóricas desenvolvidas por Pêcheux entre o materialismo e a psicanálise permitem discutir a questão do imaginário lingüístico e da subjetividade, esta última pensada aqui como manifestação simultânea de uma singularidade e de uma diferença.

O segundo eixo de minhas investigações, vinculado a estas reflexões sobre o imaginário lingüístico e sobre a constituição da subjetividade, volta-se para uma análise de colunas de consultório psicanalítico publicadas em jornais cariocas. Interessa-me analisar o circuito que se organiza entre as cartas enviadas para essas colunas de consultório e as respostas dadas pelos colunistas. Com essa análise, busco verificar o modo como a construção discursiva dessas colunas vem constituindo pragmaticamente um sentido de saúde mental que se encontra vinculado a um sentido de sujeito marcado pelo idealismo e pelo psicologismo: um sujeito onipotente, totalmente consciente, auto-suficiente, controlador e responsável por suas vontades, atos e palavras.

Parto da hipótese de que no processo de leitura dessas colunas ou seja, no circuito que se estabelece entre as cartas enviadas, as respostas produzidas pelos colunistas e os leitores dos jornais - colocase em circulação sentidos previamente estabelecidos e socialmente instituídos sobre o lugar ocupado para ser um leitor-missivista ${ }^{3}$ de um jornal determinado e sobre o que seria um bem-estar psíquico nos dias de hoje. São parâmetros que ratificam um sentido psicologizante de sujeito, já mencionado, uma concepção que acaba por reforçar a formasujeito $^{4}$ do capitalismo.

A análise compara o funcionamento discursivo de três colunas: 1) a de Eduardo Mascarenhas, intitulada No Divã do Mascarenhas, publicada entre 1983 e 1991, no jornal Última Hora; 2) a de Regina Navarro Lins, intitulada Conversando na varanda, publicada no Jornal do Brasil entre 1998 e 2001, e 3) a de Alberto Gondin, intitulada Vida Íntima, publicada em O Globo, entre 1998 e 2002.

A fim de delimitar as questões teóricas acima mencionadas, bem como introduzir outras igualmente necessárias para a apresentação da análise, destaco os pontos que serão abordados a seguir: 1) inconsciente e ideologia na constituição da subjetividade; a questão dos aparelhos

Comun. Inf., v. 7, n. 1, p.47-62, jan./jun. 2004 
de estado em sua relação com a subjetividade e a subjetividade como manifestação de singularidades e diferenças; 2) o lugar da coluna de consultório no discurso jornalístico, de que sujeito se trata nas colunas de consultório e a homogeneização da posição do sujeito-leitor e do sujeito-autor dessas colunas.

\section{Sobre a constituição do sujeito}

A análise do discurso produz uma crítica ao conceito de sujeito entendido como indivíduo, ou seja, o sujeito do humanismo, produzido pela forma do sujeito-de-direito e encoberto por uma moral psicológica. Um sujeito que se funda no esquecimento de que é um ser de linguagem antes de tudo e que, portanto, foi falado antes de falar. A crítica estabelecida por Pêcheux (1988) tem seus fundamentos a partir de uma reterritorialização de noções do materialismo e da psicanálise. Como se sustenta essa crítica?

\section{1 da psicanálise na análise do discurso}

Com Freud se dá o descentramento dessa noção de indivíduo. Postulando a hipótese do inconsciente, ou seja, uma coisa que, tendo um caráter psíquico, atua sobre o sujeito sem o seu conhecimento, Freud mostra que o sujeito não pode ser reduzido a um conteudismo consciente, ou seja, o sujeito não corresponde a um conjunto de significados pensados em termos de uma exterioridade cultural ou social. No pensamento freudiano, a hipótese do inconsciente aponta para o fato de que o sujeito é constituído por algo "que não pode tornar-se consciente". ${ }^{5}$ Daí o sujeito ser dividido, ser marcado por um inconsciente que fala no consciente sem que ele (o sujeito) controle ou domine esse processo.

Em seu retorno a Freud, Lacan mostrará que o inconsciente é a manifestação de um saber desconhecido e não familiar para o sujeito, "um sentido não antecipável, irredutível eirreconciliável". Em suma, algo totalmente sem substância, impensável, inabordável. "O inconsciente", diz Lacan, "é uma parte que falta à disposição do sujeito para restabelecer a continuidade de seu discurso consciente" . Foi relendo e ressignificando o signo saussureano que Lacan introduziu a noção de significante, o elemento que constitui o inconsciente, que tem precedência sobre o sentido e que vem do Outro ${ }^{8}$. É esse significante Comun. Inf., v. 7, n. 1, p.47-62, jan./jun. 2004 
advindo do Outro, porém não aprisionado a significações, ou melhor, precedendo ao sentido, que constitui a subjetividade: "A estrutura de linguagem pré-existe; o inconsciente é a sua condição" " E no processo de constituição da subjetividade, a cadeia significante irá estruturar cada sujeito de maneira singular em função do modo próprio como se organiza e se presentifica, seja na cristalização de determinados sentidos, ou, ao mesmo tempo, na ressignificação e na manifestação de equívocos e falhas na ordem da língua. O sujeito encontra-se sempre dividido entre o moi -"moi" ou ego-imaginário, que se perde no engano de se julgar como unidade de um dizer unívoco - e o je - o sujeito como efeito do inconsciente, representado pelo significante ${ }^{10}$. A cada falha na cadeia significante, a cada lapso cometido - marcas dessa divisão inconsciente - o sujeito imaginariamente se reconstrói como unidade, e isso se materializa na linguagem, ganhando o contorno do que mencionei anteriormente como imaginário lingüístico.

\section{2 do ideológico na constituição do sujeito}

Trago, então, as pistas deixadas por Pêcheux ao retomar Lacan e Althusser ${ }^{11}$ : o sujeito dividido, ou seja, afetado pelo inconsciente, quando diz"eu" ("ego-moi"), o faz a partir de um efeito retroativo que é resultado de sua interpelação pela ideologia. Para ter a ilusão de ser sujeito do que diz, sendo assujeitado a significantes determinados, foi necessária uma préinscrição no campo da linguagem, e isso não se realiza de qualquer maneira. Em termos discursivos mais específicos, a subjetividade se constitui na interpelação ideológica e na inscrição-identificação do sujeito na formação discursiva - matriz de sentidos - que o constitui.

É a partir dessa posição discursiva resultante de sua constituição por uma matriz de sentidos determinada, e inserido em uma relação imaginária com a "realidade" do que lhe é dado, agir, pensar no plano do teatro consciência, que o sujeito se encontra submetido à ilusória origem e ao ilusório controle dessa mesma linguagem que o constituiu como sujeito falante.

Ora, o que se tem aqui, como já foi dito, é uma anterioridade do significante produzindo a inscrição do sujeito no campo da linguagem, ou seja, o que se tem é uma dependência do sujeito ao significante. No entanto, com uma diferença. Para Pêcheux, em sua visada teórica da relação entre o inconsciente e a ideologia, essa dependência ao Comun. Inf., v. 7, n. 1, p.47-62, jan./jun. 2004 
significante, ou seja, essa inscrição no campo da linguagem não se realiza fora do ideológico. Como afirma o autor, há que se considerar a existência de "um processo do significante, na interpelação (ideológica) -identificação (simbólica)." Na constituição da subjetividade, então, ocorre um duplo processo engendrado pela inscrição do significante estruturando o inconsciente e constituindo o sujeito: uma identificação simbólica do sujeito à formação discursiva na qual ele se constitui e um assujeitamento ideológico aos sentidos que essa mesma formação discursiva, como matriz de sentidos, produz. Como nos diz Pêcheux, esse duplo processo de interpelação-identificação se encontra, porém, recalcado:

"Os significantes aparecem dessa maneira não como as peças de um jogo simbólico eterno que os determinaria, mas como aquilo que foi 'sempre-já' desprendido de um sentido: não há naturalidade do significante; o que cai, enquanto significante verbal, no domínio do inconsciente, está 'sempre-já' desligado de uma formação discursiva que lhe fornece seu sentido, a ser perdido no non-sense do significante."12

Esse "significante sempre-já desligado de uma formação discursiva", no entanto, retorna para o sujeito que nele irá colar algum sentido buscando produzir um arranjo, uma linearidade da cadeia significante e nas narrativas que constrói para si. É nesse ponto que se pode reconhecer o funcionamento do imaginário lingüístico como um processo que não tem sua origem no sujeito falante, mas nele se manifesta como resultado do funcionamento do esquecimento número 2 encobrindo o esquecimento número $1^{13}$. Dizendo de outro modo, nesse corpo verbal encontram-se os efeitos do inconsciente e da ideologia na constituição do sujeito pela linguagem. Ou ainda, podese dizer que no imaginário lingüístico se realiza um esforço (consciente) do sujeito em se assegurar como unidade linguageira, ou seja, uma espécie de 'cegueira' do sujeito em não reconhecer o funcionamento do inconsciente e da ideologia na lingua(gem).

\section{3 dos aparelhos de estado em sua relação com a subjetividade}

Como foi mencionado na seção anterior, encontra-se materialmente constituído na linguagem o vínculo do sujeito à formação discursiva Comun. Inf., v. 7, n. 1, p.47-62, jan./jun. 2004 
que o domina, vínculo esse concebido por Pêcheux como "identificação simbólica", ou seja, identificação a determinados significantes na linguagem, significantes constitutivos do sujeito do discurso como efeito. Na identificação simbólica estão inscritas, portanto, as representações verbais (termo de Pêcheux), ou seja, o resultado do efeito do assujeitamento ideológico a uma dada formação discursiva. As representações verbais vinculam-se entre si em função dos processos de reformulação parafrástica inerentes às formações discursivas. E, como efeito de haver sentido, essas representações verbais produzem uma consistência imaginária para o sujeito, ou seja, ficam impregnadas do que seriam evidências de sentidos cristalizados, que aparecem para o sujeito como únicos, óbvios, enfim, aqueles que constituem sua identidade psico-social.

Esse é o processo que constitui o chamado "teatro da consciência" e que funciona reforçando o "vínculo entre o 'sujeito de direito' (aquele que entra em relação contratual com outros sujeitos de direito; seus iguais) e o sujeito ideológico (aquele que diz ao falar de si mesmo: 'Sou eu!')."'14

Considerando a questão da subjetividade em sua constituição pela ideologia, ou seja, considerando o sujeito em sua interpelação ideológica, Orlandi dirá que "não é pelo conteúdo que a ideologia afeta o sujeito, é na estrutura mesma pela qual o sujeito (e o sentido) funciona." 15 Visando compreender de que modo a ideologia "leva ao equívoco da impressão idealista da origem em si mesmo do sujeito"16, a autora apresenta o que chama de "um duplo movimento da subjetividade".

Em um primeiro momento, e entendendo que o processo significante que afeta o sujeito não é a-histórico, encontra-se justamente a interpelação do indivíduo em sujeito pela ideologia. Ainterpelação produz assujeitamento e isso ocorre em qualquer época histórica, em quaisquer que sejam as condições de produção, pois resulta da inscrição do sujeito no simbólico e, ao mesmo tempo, produz como resultado que esse sujeito, afetado pelo simbólico, expresse a sua subjetividade na ilusão de autonomia e de ser origem do seu dizer. "A forma-sujeito, que resulta dessa interpelação pela ideologia, é uma forma-sujeito histórica, com sua materialidade." 17

Em um segundo momento (que não corresponde necessariamente,

Comun. Inf., v. 7, n. 1, p.47-62, jan./jun. 2004 
deve-se ressaltar, a uma temporalidade expressa em dias ou anos), ocorre um "estabelecimento (e transformação) das formas de individua(liza)ção do sujeito em relação ao Estado." Em outras palavras, ocorre uma individualização histórica da forma-sujeito em função da inserção do sujeito nas relações sociais regidas pelas instituições que são reguladas pelo Estado. Do indivíduo interpelado em sujeito ( $\left.\mathrm{I}^{1}\right)$ resulta o sujeito em "sua forma individualizada concreta $\left(I^{2}\right)$ ", ou seja, aquela que visa a adaptação do sujeito no social. Como afirma a autora, "no caso do capitalismo, que é o caso presente, a forma de um indivíduo livre de coerções e responsável, que deve assim responder, como sujeito jurídico (sujeito de direitos e deveres), diante do Estado e de outros homens."18

\section{4 do sujeito como singularidade e diferença}

Como fica a questão da singularidade na constituição da subjetividade? Qual o papel da interpelação ideológica em seu processo de uniformização do teatro da consciência, regido, em última instância, pelas instituições? Como fica a singularidade subjetiva em face da interpelação ideológica?

Em parte, essa questão já foi respondida quando se mencionou que há um modo específico de inscrição do significante em cada sujeito. Acrescente-se a isso que, no modo como Pêcheux descreve o processo ideológico de interpelação-identificação, verifica-se que se trata de um processo do significante nunca completo ou absoluto. É o que faz com que a falha também seja constitutiva do sujeito. Além disso, Orlandi nos lembra que esse processo de subjetivação ideológica no simbólico funciona pela forma do equívoco, produzindo como efeito a possibilidade de resistência quanto ao modo de sua individualização pelo Estado.

Pode-se levar em consideração nessas respostas, também, o fato de que a singularidade aponta para o heterogêneo, para o descontínuo. Falar em questões de singularidade, portanto, é tocar na questão da produção de diferenças subjetivas que se marcam no campo do homogêneo e contínuo. ${ }^{19}$ Assim sendo, vale a pena retomar o que foi dito sobre a constituição da subjetividade, considerando essa contradição entre o homogêneo e o heterogêneo causada pela singularidade como produção de diferenças.

Comun. Inf., v. 7, n. 1, p.47-62, jan./jun. 2004 
Falemos, então, do sujeito da diferença, do ponto de vista da psicanálise. Em primeiro lugar, a singularidade pode remeter para o que se encontraria bastante fora da ordem cultural, indo ao encontro, nesse sentido, do excêntrico, do exibicionismo, da perversão. Mas não é dessa diferença que se trata aqui.

Interessa, aqui, trabalhar com a singularidade que, mesmo tendo como pano de fundo uma pressão de homogeneidade, mostra-se como diferença. Tal singularidade, se for resultado de um modo próprio de constituição do sujeito pelo significante, resulta também daquilo que não se inscreve pela via do significante, ou seja, em termos freudianos, um algo a mais inscrito no aparelho psíquico e não absorvido no simbólico: a força das pulsões. Como afirma Birman, "este algo, pólo da fundação das diferenças subjetivas, é o que permite e indica a existência de um eu sinto que não se conjuga como eu devo do imperativo categórico freudiano. (...) Esta diferença mínima entre o eu sinto e o eu devo é o que pode permitir que o sujeito constitua um estilo singular de existência, marcando de maneira radical sua diferença face a qualquer outro sujeito." 20

Se o eu devo resulta da entrada do sujeito no simbólico, se estar no simbólico é estar na linguagem, com sua ordem própria, com um trabalho de administração das significações sustentado pelo 'eu' (Ego, moi), por outro lado, não se pode esquecer que a própria língua é um sistema de significantes regido por oposições e diferenças. ${ }^{21} \mathrm{E}$, mais, as ausências contam na língua: a língua é não-toda, ou seja, "o todo da língua só existe constituído pelo signo ausente, pelo não dito. ${ }^{22}$ Assim, ainda de acordo com Birman, "a exigência de diferença possibilitada pelo corpo pulsional se inscreve num campo representacional marcado pela diferença. Enfim, a produção da diferença encontra as suas condições de possibilidades nos registros pulsional e simbólico, e na passagem do primeiro para o segundo." ${ }^{23}$

Dito de outra maneira, para haver constituição do sujeito é necessário a desordem das forças pulsionais estar submetida à inscrição no simbólico. Em termos lacanianos, essa desordem é da ordem do impossível: há um impossível de ser dito que insiste e retorna, causando estranhamento para o sujeito.

Em resumo, a subjetividade - no que ela se mostra, no que se esconde, no que é repetição ou equívoco, no que se marca como Comun. Inf., v. 7, n. 1, p.47-62, jan./jun. 2004 
diferença, no que se inscreve como homogeneidade - resulta do acontecimento da linguagem ${ }^{24}$ no sujeito. Um acontecimento que tanto possibilita a singularização da diferença quanto a regulação do sujeito, relativamente a uma universal adaptação à ordem cultural, e social por meio do mesmo simbólico que o constituiu.

\section{Sobre as colunas de consultório e a psicanálise no discurso jornalístico}

Parto de uma série de reflexões já realizadas sobre o discurso produzido pela imprensa de referência. ${ }^{25}$ Trata-se, como já tive a ocasião de dizer em outros momentos, de uma prática discursiva que atua na construção e reprodução de sentidos, prática essa realizada a partir de um efeito ilusório da função do jornal como responsável apenas por uma transmissão objetiva de informações. O discurso jornalístico constrói-se, dessa forma, com base em um pretenso domínio da referencialidade, pois se baseia em uma concepção de linguagem que considera a língua como instrumento de comunicação de informações. Decorrem daí vários efeitos constitutivos dos sentidos veiculados como informações jornalísticas: objetividade, neutralidade, imparcialidade e veracidade.

Além disso, essa pretensa informatividade jornalística se sustenta com base em uma ideologia utilitária, ou seja, parte-se de um pressuposto (construído historicamente na relação entre jornais e leitores) de uma necessidade social de saber os fatos relatados. Estes, dessa forma, já figuram nas páginas impressas pré-significados por uma relevância constituída pelo imaginário: se o jornal publicou é porque é importante ou só é importante o que aparece no jornal. Fica apagado para o leitor o fato de ter havido uma seleção das notícias (a pauta), ficando igualmente apagado que as manchetes também resultam de tomadas de decisão realizadas pelos editores e assim por diante.

Leitores e jornalistas encontram-se, dessa maneira, enquadrados nos domínios de pensamento de sua época, ficando imersos em uma agenda (organizada pelos 'donos' do jornal) previamente constituída por interpretações legitimadas ou já tomadas como socialmente consensuais, ou que virão a se tornar consenso por força, exatamente, dos efeitos produzidos pela própria imprensa. É possível afirmar, então, que há uma ritualização ideológica presente no discurso jornalístico, Comun. Inf., v. 7, n. 1, p.47-62, jan./jun. 2004 
entendendo ritualização aqui como uma forma de manutenção e repetição de determinados sentidos.

\section{1 as colunas de consultório no discurso jornalístico: um paradoxo?}

Paradoxalmente, essa noção "higiênica de informação"26 dos fatos encontra-se afetada nas colunas de consultório: em vez de uma voz impessoal, responsável por um relato que se pretende imparcial, objetivo e útil, encontra-se uma voz que, narrando em primeira pessoa, faz o relato de um problema absolutamente pessoal, de modo completamente subjetivo e, muito possivelmente, sem interesse social. Se retomamos a afirmação de Pêcheux de que não há ritual sem falhas, essas colunas corresponderiam a uma falha nesse ritual ideologicamente construído da informatividade jornalística?

Em princípio, a resposta para a questão é afirmativa. Afinal, as colunas representam um lugar de produção de um sentido outro, um sentido estranho ao discurso jornalístico. São sítios de significância duplamente subjetivados e dialogicamente organizados: de um lado, cartas de leitores dirigidas a psicanalistas; de outro, respostas fornecidas por psicanalistas (supostamente) com base no saber psicanalítico.

Seria possível considerar, então, que essas colunas constituem uma brecha, uma rachadura, uma falha no ritual ideológico jornalístico de apresentação da "verdade" de fatos que falam por si, cujo suporte seria a língua, entendida como instrumento de comunicação de informações. ${ }^{27} \mathrm{O}$ que provoca a falha é a irrupção de uma subjetividade, de uma pessoalidade: a carta apresenta um problema pessoal, um sofrimento particular e singularizado. Assim, as colunas estariam fomentando duas fraturas nesse ritual: a irrupção de uma subjetividade, de uma pessoalidade, como já foi dito, e, também, o acolhimento do discurso psicanalítico como lugar de respostas para os problemas apresentados.

Qual a pertinência, então, de tais colunas em meio ao discurso jornalístico? Elas corresponderiam a ilhas de subjetividade voltadas para leitores curiosos em saber da vida alheia, sua pertinência estariana acolhida a uma espécie de voyeurismo consensual e socialmente aceito.

Ora, se assim for, essa resposta inicial, que supõe as colunas como lugares de falha no ritual jornalístico, precisa ser mais trabalhada. Afinal, Comun. Inf., v. 7, n. 1, p.47-62, jan./jun. 2004 
quando se tematiza a questão da falha em termos discursivos, está-se falando de uma fratura no ritual ideológico, que resulta na produção de um acontecimento: na relação sujeito-língua-história é a instauração de um lapso lingüístico, de um equívoco histórico, é a presentificação, enfim, de um sentido não previsto que pode vir a produzir um deslocamento, uma reviravolta para o sujeito, para a história. Desta forma, uma vez instalada uma fratura em rituais ideológicos, dois são os desdobramentos socialmente possíveis, dois são os destinos para o sentido inesperado: a falha, como lugar de resistência, pode engendrar rupturas e, conseqüentemente, transformação do ritual, ou, por outro lado, pode vir a ser absorvida pelo discurso hegemônico, contribuindo para a permanência dos sentidos legitimados historicamente.

Um exame detalhado das colunas aponta para o segundo desdobramento, ou seja, as colunas, tal como se apresentam nos jornais atualmente, e porque estão inseridas nesse discurso, sofrem os efeitos desse imaginário jornalístico da imparcialidade, veracidade, etc. Por essa via, em vez de fraturar o ritual, reforçam os domínios de pensamento de nossa época em um aspecto específico: promovem a idealização do sujeito centrado e autônomo, capaz de decidir sobre seu destino, ou melhor, responsável pela felicidade ou infelicidade de seu futuro. As cartas e as respostas teatralizam a consciência do "eu" (ego, moi), idealizando, em nome da psicanálise, comportamentos socioculturalmente admissíveis.

Foi possível observarque o discurso produzido em tais colunas funciona como um meio no qual são imaginarizadas representações de sujeito que podem vir a atuar na formação de uma subjetividade homogênea e coletivamente disseminada, pois apresentam e descrevem idealmente determinados modos de estar-no-mundo para o sujeito leitor. É o que mostrarei a seguir.

\subsection{Reforçando o ritual do teatro da consciência}

Antes de mais nada, deve-se ter em mente que tais colunas se constituem como espaços previamente marcados e autorizados pelo próprio discurso jornalístico para a apresentação de narrativas de problemas pessoais. Trata-se de uma falha ritual autorizada, por assim dizer. E sendo autorizada, não constitui uma possibilidade de ameaça ao ritual. A questão é: quais os efeitos de sua inserção no discurso jornalístico e até que ponto as colunas reforçam a ilusão de neutralidade Comun. Inf., v. 7, n. 1, p.47-62, jan./jun. 2004 
e veracidade desse mesmo discurso?

Se os leitores que escrevem são anônimos (valendo-se de pseudônimos na assinatura da carta), os colunistas são sujeitos que, ocupando um lugar de psicanalista, têm seus nomes divulgados, inclusive, em outros espaços do jornal, pois emitem opiniões sobre eventos, novelas, têm seus livros resenhados etc. Falam de um lugar de autoridade - são doutores, seus títulos aparecem junto com seus nomes - estabelecido com o auxílio do próprio jornal e, dessa forma, a eles são atribuídos uma competência e um poder de dizer a verdade.

Antes de prosseguir, é relevante dizer alguns aspectos sobre as condições de produção do discurso psicanalítico na imprensa. Já há algum tempo vem ocorrendo uma maior difusão social das idéias psicanalíticas. E a forma como essa difusão vem se fazendo, de algum modo, induz a uma legitimação da psicanálise como lugar de produção de saber, mas transforma esse saber e os conceitos a ele pertinentes em uma "moral laica". Como afirma Birman, desde os anos 1960 e a partir de uma americanização do pensamento freudiano, "a psicanálise foi transformada numa visão de mundo, numa moral para a modelagem da individualidade às múltiplas exigências da sociedade complexa. (...) A psicanálise é apresentada como um código fechado onde as individualidades encontram um mapa com direções infalíveis para seus percursos na incerteza da existência." 28

Se Freud e Lacan mostram-se compromissados com uma ética sustentada na questão do desejo, se ambos são pessimistas quanto aos destinos desse sujeito desejante, a leitura que se encontra na imprensa, e mais especificamente nessas colunas, ao contrário, coloca a psicanálise como um lugar de promoção da felicidade. Em nome da psicanálise, o que se lê nas colunas é uma valorização psicológica do sujeito, colocada lado a lado de matérias sobre novos medicamentos, livros de auto-ajuda, recentes descobertas da medicina, dicas para manter a saúde perfeita, dietas saudáveis, roupas adequadas para a saudável prática de esportes, enfim, um receituário bem disfarçado, fornecendo informações sobre as supostas necessidades do leitor, um sujeito urbano.

Assim, um psicanalista, ao ocupar o lugar de um colunista, defrontase com essa imagem pré-construída e socialmente aceita sobre seu saber: um saber voltado para a divulgação de explicações e soluções Comun. Inf., v. 7, n. 1, p.47-62, jan./jun. 2004 
de problemas, assim como as demais matérias presentes no mesmo caderno. Cabe ao psicanalista apaziguar, tirar dúvidas e dar conselhos sobre modos de existência na sociedade, da mesma forma que as outras matérias e colunas tiram dúvidas sobre moda, gastronomia, doenças, direito legal etc.

A leitura das cartas, por sua vez, aponta para um eixo temático majoritariamente comum: questões amorosas insatisfeitas e opções sexuais igualmente insatisfeitas, gerando dilemas morais e impasses sobre atitudes a serem tomadas. Foi interessante observar o quanto as cartas se parecem entre si, constituindo um conjunto de imagens do "eu" bastante assemelhadas. A uniformização temática funciona de modo a apagar as diferenças subjetivas, produzindo uma homogeneização das singularidades. Aos olhos dos leitores, missivistas ou não, a vida fica reduzida a casamentos infelizes, a adolescências traumáticas ou a opções sexuais frustradas. No lugar das diferenças subjetivas, o que se encontra é um conjunto de relatos individualizados, girando em torno de uma mesma temática e produzindo um efeito de naturalização sobre o tipo de problema que se tem na contemporaneidade.

Como nos lembra Pêcheux, "o subjetivo simula o objetivo". É a partir de relatos individuais, feitos por sujeitos "concretos", membros de uma mesma comunidade, que vão sendo construídas soluções reguladas, visando a adaptação desses sujeitos concretos à ordem sociocultural vigente. Esse conjunto de imagens do "eu" acaba funcionando como um único sujeito e, ao se inscrever no discurso jornalístico, torna-se partícipe do efeito de objetividade, reforçando o teatro da consciência do que é dado a pensar e dos sentidos possíveis de serem ditos (e vividos).

A partir da leitura das cartas e das respostas dadas pelos colunistas, os leitores, missivistas ou não, imaginarizar identificações ("se eu estivesse onde você/ele/x se encontra, eu veria e pensaria o que você/ ele/x vê e pensa"29) que apagam as descontinuidades e o heterogêneo e produzem uma ilusão de consenso tanto no que se refere à questão relatada (todos temos o mesmo tipo de problemas) quanto ao tipo de solução proposta pelo colunista-psicanalista [todos pode(ría)mos resolver da mesma forma]. O individual, dessa forma, serve como modelo de subjetividade coletiva, além de funcionar como suporte para a normalização moral das relações sociais.

Comun. Inf., v. 7, n. 1, p.47-62, jan./jun. 2004 
Para finalizar, retomando também as observações de Orlandi, “o que fica de fora quando se pensa o sujeito já individualizado é justamente o simbólico, o histórico e a ideologia, que tornam possível a interpelação do indivíduo em sujeito." 30 E eu ainda acrescentaria: nas colunas de psicanálise fica de fora também o inconsciente, como lugar em que o sujeito falha, e que pode estar apontando justamente para essa moral reguladora das relações sociais.

\section{Referências}

BIRMAN, Joel. Psicanálise, ciência e cultura. Rio de Janeiro, Jorge Zahar Editor, 1994.

34, 1997.

. Estilo e modernidade em psicanálise. São Paulo, Editors

JURAINVILLE, Alain. Lacan e a filosofia. Rio de Janeiro, Jorge Zahar Editor, 1995.

LACAN, J. O seminário livro 11; os quatro conceitos fundamentais da psicanálise. Jorge Zahar Editor, 1996.

. Escritos. Rio de Janeiro, Jorge Zahar Editor, 1998.

LE GAUFEY, Guy. L'incomplétude du symbolique. Paris, E.P.E.L., 1996.

MARIANI, Bethania. $O P C B$ e a imprensa; os comunistas no imaginário dos jornais. Rio de Janeiro e Campinas, Editora Revan \& ed. Da Unicamp, 1998.

em (dis)curso. No 03 Especial sobre subjetividade. Tubarão, Editora da UNISUL, 2003.

ORLANDI, Eni P. Discurso e texto; formulação e circulação dos sentidos. Campinas, Pontes, 2001.

ORLANDI, Eni P. Interpretação. Petrópolis: Vozes, 1996.

PÊCHEUX, Michel. Semântica e discurso; uma crítica à afirmação do óbvio. Campinas, Editora da Unicamp, 1988.

Pêcheux, Michel. A lingual inatingível. Campinas, Pontes, 2004.

\section{Notas}

'Lacan, 1998, pg. 124.

Comun. Inf., v. 7, n. 1, p.48-63, jan./jun. 2004 
${ }^{2} \mathrm{Cf}$. mais detalhadamente Mariani, 2003.

${ }^{3}$ Um leitor missivista que é também leitor da coluna e do jornal.

${ }^{4}$ Pêcheux, 1998, pg. 170.

${ }^{5}$ Jurainville, 1995, p. 31.

${ }^{6}$ Considerando que "...o inconsciente é aquilo que não pode tornarse consciente" , o que é a consciência? Segundo Jurainville, "quando se toma consciência, verifica-se aquilo que já se sabia-sem que justamente isso seja colocado como tal. (...) A consciência tem um pressuposto esse saber, que será preciso determinar - contra cujo fundo ela se desenha como verificação, ou melhor, comprovação 'de que é isso mesmo' (...) Que é então que caracteriza essa anterioridade na consciência? É a atribuição de um sentido. (...) o que se produz com a consciência: um sentido que era antecipado é 'verificado', ou melhor, comprovado no presente - re-constituído. (...) Deveremos então indagar-nos se não poderíamos conceber um sentido que de modo algum fosse antecipável. Se ele existisse, seria então perfeitamente certo que nos encontraríamos diante daquilo a que se deveria chamar $o$ inconsciente, no sentido daquilo que não pode tornar-se consciente." (JURAINVILLE, 1995, pgs 31 a 39)

${ }^{7}$ Lacan, 1998, pg.260.

${ }^{8}$ O grande "Autre" lacaniano - isto é, o simbólico, o Outro da linguagem, "tesouro de significantes", o inconsciente como "discurso do Outro" (Lacan, op. cit, pg. 529; cf. Le Gaufey, 1996, p. 186).

${ }^{9}$ Lacan, Seminário 11, pg 26.

${ }^{10}$ Essa distinção entre o moi e o je, proposta por Lacan, não apresenta equivalência, em termos de uma tradução, no português.

"Pêcheux, 1988, p. 163.

Pêcheux, 1988, pg. 176.

${ }^{13}$ Em seu processo de constituição, o sujeito falante é afetado por uma dupla ilusão: uma primeira, de ser fonte e origem dos seus dizeres (ilusãoesquecimento $\mathrm{n}^{\circ} 1$ e é de natureza inconsciente), e uma segunda, de ter o domínio do que diz, sendo totalmente capaz de dominar e manipular estratégias enunciativas (é ilusão-esquecimento $\mathrm{n}^{\circ} 2$ e é de natureza pré-consciente).

${ }^{14}$ Pêcheux, op. cit., pg. 154.

${ }^{15}$ Orlandi, 2001, pg. 104.

16 Idem, pg. 71

${ }^{17} i d$., $i b i d$, e que corresponde ao que Orlandi chama de $\mathrm{I}^{1}$.

${ }^{18}$ Orlandi, idem, pg. 105.

Comun. Inf., v. 7, n. 1, p.478-62, jan./jun. 2004 
${ }^{19}$ Cf. Birman, 1994, pg. 152.

${ }^{20}$ Birman, op. cit, pg. 150

${ }^{21}$ Birman, op. ci., pg. 151

${ }^{22}$ Pêcheux, La langue introuvable, pg. 56

${ }^{23}$ id., ibid.

${ }^{24}$ Guimarães, partindo de outras questões, irá conceituar a enunciação, afirmando: "Acontecimento no qual se dá a relação do sujeito com a língua" (2000, pg. 4).

${ }^{25}$ Cf. Mariani, 1998.

${ }^{26}$ Pêcheux, A língua inatingível

${ }^{27}$ Mariani ( 1998) já havia feito uma menção às charges e às caricaturas como lugares de instalação de falhas no ritual jornalístico.

${ }^{28}$ Birman, 1994, pg 121

${ }^{29}$ Pêcheux, 1988, pg. 128

${ }^{30}$ Orlandi, 2001, pg. 106

Comun. Inf., v. 7, n. 1, p.47-62, jan./jun. 2004 